shallow and unsophisticated. Whether Loeb's scientific career should be interpreted in terms of the contrasting reductionist and anti-reductionist research strategies is, however, open to question. To be opposed to localization theories of the functioning of the cerebral cortex does not entail opposition to physico-chemical explanations of brain processes. Loeb's holism was not at odds with his reductionism - we just need to be careful what we mean when we apply the term reductionist to him.

Two contrasting approaches which are surely more appropriate to his work are those of dynamical and structural explanations. Among the former are vibrations, patterns, gradients, fields (all of them dynamic organizations due to continuing physical processes), whereas structural explanations refer to persistent morphological entities (chromosomes, nucleoli, cytoplasmic particles) whose existence does not depend on continuing processes. Loeb, like d'Arcy Wentworth Thomson and William Bateson, relied on dynamical explanations. Loeb turned to colloidal systems and to the Donnan equilibrium, Thomson and Bateson to analogies with magnetic fields, sound waves, sand ripples, and the stresses and strains of bridges. All three were opposed to Weismannian preformation and the artefacts of the cytologists. Yet it was the successes of the cytologists and cytogeneticists which justified the identification of morphological structures in the cell as causal agents of its behaviour. No wonder Loeb, like Bateson, seemed to have lost his way in biology and only rescued his reputation by his study of the physical chemistry of the proteins.

Robert Olby is Reader in the Division of History and Philosophy of Science, Department of Philosophy, University of Leeds, Leeds LS2 9JT, UK.

\section{High society}

David E. Allen

A Bicentenary History of the Linnean Society of London. By Andrew Thomas Gage and William Thomas Stearn. Academic: 1988. Pp.241.£25, $\$ 49.50$.

"THE world's oldest active biological society", the Linnean ranks in seniority second only to the Royal in that pantheon of learned bodies, steeped in history and majestically housed, which for so long constituted 'Scientific London'. Through their meetings and their journals, the two societies continue to play a leading role not only in the metropolis but far beyond. The Linnean, however, has the extra and unique function of acting as international caretaker of the collections of type specimens which were the original pretext for its founding, and on which the whole huge edifice of biological nomenclature ultimately rests. The rooms in Burlington House, the society's home since 1873, consequently double up as what is effectively a shrine.

Such a body can hardly help but be proudly conscious of its past, and it was unthinkable that the series of events with which it is celebrating its bicentenary should not have included a volume updating the story of its life. There was a problem, however, in deciding how best his should be done. For, awkwardly, the first century and a half were thoroughly chronicled in 1938 by A.T. Gage, one of the society's former executive officers. Though clogged with too much loving detail, and not very enthrallingly written, Gage's history was too substantial to be disregarded lightly.

To have gone over that ground all altogether different pattern that he had chosen to follow from the start.

Had he not had to work within these preordained bounds, Stearn would surely not have arrived at the conclusion, as he does in his preface, wistfully and halfapologetically, that "on the whole the Society's life has seemed unexciting, almost at times lethargic". For there is much in the surviving records from which a livelier tale could have been extracted by a pen more agile and experienced than Gage's. Even the second quarter of the nineteenth century - when the society had beggared itself in purchasing Linnaeus's collections and had fallen under the sway of a deadeningly unimaginative group of elders - was the occasion of many a colourful shaft in the published and unpublished literature which it would have been helpful to have disinterred. The personality of the founder, James Edward Smith, needs a less sparing analysis than it has received as yet, and there is reason to believe that the circumstances of the society's birth were considerably more complicated than the received account suggests.

The famous meeting of 1 July 1858 , at which the papers of Darwin and Wallace were read jointly (in the absence of their authors), is well described and the reasons for their failure to make an impact are examined in justifiable detail; at the same time it is hard to believe that the Darwin industry has not now uncovered a greater range of letters to enable the affair to be documented more thoroughly. Gage was good, too, on the long and contorted struggle that had to take place before women were admitted as Fellows, but his account ought to have been amplified by the more recent research which would have enabled it to be seen within a wider context. In the same way, more comparisons with the experience of the Linnean's sister societies in London, in particular its offshoots, the Zoological and the Royal Entomological, would have been enlightening: Gage's view was too myopically domestic.

All the same there is an enormous mass of information here that historians of science will be eager to quarry. The Linnean Society has played such a central part on the natural-history-cum-biological stage over such a lengthy span of years that no student of the development of biology or scientific institutions can afford to bypass its extraordinarily comprehensive records - or the many collections of letters that so richly augment them. In preparation for their visits, historians will assuredly find this volume to be an indispensable introduction.

David E. Allen is in the Unit of History of Medicine, University College London, Gower Street, London WCIE 6BT, UK, and author of The Botanists: a History of the Botanical Society of the British Isles through 150 Years (St Paul's Bibliographies, 1986). 